\section{Atherogenic Ratios in Patients with Recurrent Acute Coronary Syndrome and Receiving Statin Therapy: Clinical Usefullness as Cardiovascular Predictors}

Maria Ferrer Civeira ${ }^{1}$, Juan Pedro-Botet ${ }^{2,3}$, Xavier Pintó ${ }^{4}$, Manuel Zúñiga ${ }^{5}$, Alipio Mangas ${ }^{6}$, Antonio Hernandez-Mijares ${ }^{7}$, Emili Corbella ${ }^{4}$, and Jesus Millan Nuñez-Cortes ${ }^{1,8^{*}}$

${ }^{1}$ Vascular Risk and Lipid Unit, Department of Internal Medicine, Hospital General Universitario Gregorio Marañón, Madrid, Spain

${ }^{2}$ Vascular Risk and Lipid Unit, Department of Endocrinology and Nutrition, Hospital del Mar, Barcelona, Spain

${ }^{3}$ Department of Medicine, Universitat Autònoma de Barcelona, Barcelona, Spain

${ }^{4}$ Vascular Risk and Lipid Unit, Department of Internal Medicine, Hospital de Belvitge, Barcelona, Spain

${ }^{5}$ Vascular Risk and Lipid Unit, Department of Medicine, Hospital Universitario Marqués de Valdecilla, Santander, Spain

${ }^{6}$ Lipid Unit, Department of Internal Medicine, Hospital Universitario Puerta del Mar, Cádiz, Spain

${ }^{7}$ Lipid Unit, Department of Endocrinology, Hospital Universitario Dr. Peset, Valencia, Spain

${ }^{8}$ Department of Medicine, Faculty of Medicine at the Universidad Complutense, Madrid, Spain

*Corresponding author: Jesús Millán Núñez-Cortés, Vascular Risk and Lipid Unit, Department of Internal Medicine, Hospital General Universitario Gregorio Marañón, Faculty of Medicine at the Universidad Complutense, Dr. Esquerdo 46. 28007 Madrid, Spain; Tel- 91 394 1325, E-mail: jesus.millan.nunezcortes@madrid.org

Received date: July 09, 2014; Accepted date: February 05, 2015; Published date: February 14, 2015

Copyright: (c) 2015 Civeira MF et al. This is an open-access article distributed under the terms of the Creative Commons Attribution License, which permits unrestricted use, distribution, and reproduction in any medium, provided the original author and source are credited.

\section{Abstract}

Patients who have already suffered a vascular event require more and better control of cardiovascular risk factors. Different atherogenic indexes such as TC/HDLc, LDLc/HDLc, apoB/apoA-I, LDLc/apoB and non-HDLc/HDLc have been used to follow-up the patients because of their predictive capacity of the lipid profile. The aim of this study was to evaluate atherogenic ratios as a marker of the lipid residual risk in high-risk patients receiving statin therapy and to know the changes produced by previous lipid-lowering drugs treatment for a previous coronary event.

The study including patients admitted to coronary care units of six Spanish tertiary hospitals for Acute Coronary Syndrome (ACS). A total of 633 ACS patients were included; of these, $478(75.8 \%)$ had presented a myocardial infarction and $153(24.2 \%)$ angina. A previous ACS had occurred in $43.1 \%$ of cases, and was the first episode in $56.9 \%$ of the studied patients.

Among patients with known ischemic heart disease, $187(52.2 \%)$ were receiving lipid-lowering drugs, mainly statins (182 patients, $50.7 \%)$. Of those with a first ACS, $59(21.7 \%)$ were on lipid-lowering drugs: 55 (20.1\%) statins and $4(1.7 \%)$ fibrates. Patients with recurrent ACS had similar triglyceride and HDLc levels, but significantly lower total cholesterol and LDLc concentrations compared with those presenting the first ACS. Patients with recurrent ACS had significantly lower non-HDLc levels, TC/HDLc and LDLc/HDLc, but higher HDLc/TC and HDLc/LDLc ratios compared with first ACS patients.

In patients taking statins the lipid residual vascular risk was related with the persistence of cardiovascular risk factors, and related with lipid profile with dyslipemia no-LDL dependent. So, we can conclude that the correction of lipid profile by statin is not per se sufficient to control cardiovascular risk.

\section{Introduction}

Cardiovascular disease is the major cause of premature death in Spain, as in other western countries, and underlies a great deal of disability. Consequently, patients who have already suffered a vascular event require more and better risk control [1]. Although low-density lipoprotein cholesterol (LDLc) is the traditional marker for cardiovascular risk and monitoring of statin therapy, it has been emphasized that cardiovascular disease management based exclusively on this lipid parameter might not be sufficient $[2,3]$. For this reason, therapeutic guidelines, though based on LDLc as the principal target of lipid-lowering therapy, also consider other lipid factors like non HighDensity Lipoprotein cholesterol (HDLc), apoprotein (apo) B, apo A-I and the total cholesterol (TC)/HDLc, some of which can be better predictors of cardiovascular risk than LDLc alone [4,5]. However, debate on the choice of the best lipid parameter has intensified, with apparently conflicting evidence among prospective studies [6-8].

Different atherogenic indexes such as TC/HDLc, LDLc/HDLc, apoB/apoA-I, LDLc/apoB and non-HDLc/HDLc have been defined in an attempt to optimize the predictive capacity of the lipid profile [9], the efficiency of which has been demonstrated [10-12]. Although these indexes can provide information on risk factors difficult to quantify by routine analysis, and could better mirror the metabolic and clinical interactions among lipid fractions, they are under-used in cardiovascular disease prevention.

Thus, the aim of the present study was to establish atherogenic ratios, as a marker of the atherogenicity/anti-atherogenicity balance in patients with high vascular risk receiving statin therapy, for detecting the treatable residual risk. To this end, in a cohort of Spanish patients 
Citation: Civeira MF, Pedro-Botet J, Pintó X, Zúñiga M, Mangas A, et al. (2015) Atherogenic Ratios in Patients with Recurrent Acute Coronary Syndrome and Receiving Statin Therapy: Clinical Usefullness as Cardiovascular Predictors. J Clin Exp Cardiolog 6: 358 . doi: $10.4172 / 2155-9880.1000358$

Page 2 of 4

hospitalized with Acute Coronary Syndromes (ACS), patients presenting the first episode are compared with those with previous ischemic heart disease. This study will further evaluate the changes produced by previous treatments and highlight the residual risk these patients still have, even while still on lipid-lowering therapy for a previous coronary event.

\section{Material and Methods}

Medical records of patients admitted to coronary care units of 6 Spanish tertiary hospitals for ACS between January 2004 and September 2007 were selected based on the following inclusion criteria: a) availability of lipid profile at admission, including total cholesterol, triglycerides and HDLc, and b) lipid-lowering drugs prior to admission. ACS was defined according to European/American recommendations [13,14]. Age, sex, anthropometric parameters, smoking status (classified as non-smoker, smoker and ex-smoker), hypertension and type- 2 diabetes were retrospectively assessed from the clinical records. A total of 633 ACS patients were included in the study. Of these, $478(75.8 \%)$ had presented a myocardial infarction and $153(24.2 \%)$ angina. A previous ACS had occurred in $43.1 \%$ of cases, and was the first episode in $56.9 \%$.

LDLc concentration was calculated by the Friedewald formula [15]. The different atherogenic indexes analyzed in each patient were: nonHDLc, TC/HDLc, LDLc/HDLc, HDLc/TC, HDLc/LDLc and log (triglycerides/HDLc). The study was authorized by the corresponding Clinical Research Ethics Committees of the participating centres.

Statistical analyses were made with the chi-square test and the Fisher's exact test for categorical variables and the ANOVA test to study the differences among variables. A $p$ value $<0.05$ was considered statistically significant. All statistical analyses were performed using the Statistical Package for Social Sciences (SPSS) for Windows software, v. 11.5; Chicago, Illinois, United States.

\section{Results}

Of the 633 patients studied, 505 (79.8\%) were men and 128 (20.2\%) women. Clinical characteristics of the study population are summarized in Table 1 . Patients with recurrent ACS were significantly younger, fewer were smokers, and had a higher percentage of hypertension and type- 2 diabetes, with angina being the most common presentation form of ACS compared with those suffering a first episode.

Among patients with known ischemic heart disease, 187 (52.2\%) were receiving lipid-lowering drugs, mainly statins (182 patients, $50.7 \%$ ) and, more rarely, fibrates (5 patients, $2.6 \%$ ). Of those with a first ACS, 59 (21.7\%) were on lipid-lowering drugs: 55 (20.1\%) statins and $4(1.7 \%)$ fibrates.

\begin{tabular}{|l|l|l|l|}
\hline & $\begin{array}{l}\text { Previous IHD } \\
(\mathbf{n = 2 7 4 )}\end{array}$ & $\begin{array}{l}\text { No previous } \\
\text { IHD (n=359) }\end{array}$ & $\mathbf{p}$ \\
\hline Age, yrs & 60.82 & 65.83 & $0.000(1)$ \\
\hline $\begin{array}{l}\text { Sex: Male } \\
\text { Female }\end{array}$ & $\begin{array}{l}278(82.8 \%) \\
81(17.2 \%)\end{array}$ & $\begin{array}{l}227(77.4 \%) \\
47(22.6 \%)\end{array}$ & $0.057(1)$ \\
\hline $\begin{array}{l}\text { Tobacco: Smoker } \\
\text { Ex-smoker }\end{array}$ & $79(29.3 \%)$ & $169(47.9 \%)$ & $0.000(2)$ \\
Non-smoker & $124(45.9 \%)$ & $87(24.6 \%)$ & \\
$67(24.8 \%)$ & $97(27.5 \%)$ & \\
\hline
\end{tabular}

\begin{tabular}{|l|l|l|l|}
\hline BMI, $\mathrm{Kg} / \mathbf{m}^{2}$ & 28.23 & 28.55 & $0.380(3)$ \\
\hline Hypertension & $193(72.0 \%)$ & $185(52.0 \%)$ & $0.000(1)$ \\
\hline Type 2 diabetes & $1204(4.3 \%)$ & $81(23.1 \%)$ & $0.000(1)$ \\
\hline AMI as a manifestation of ACS & $185(68.3 \%)$ & $297(83.4 \%)$ & $0.000(1)$ \\
\hline $\begin{array}{l}\text { Angina as a manifestation of } \\
\text { ACS }\end{array}$ & $92(33.9 \%)$ & $61(17.1 \%)$ & $0.000(1)$ \\
\hline
\end{tabular}

Table 1: Characteristics of the 633 patients with acute coronary syndrome, according to a history of ischemic heart disease. (1) Fisher exact test, (2) chi-squared, (3) Anova test.

Patients with recurrent ACS had similar triglyceride and HDLc levels, but significantly lower total cholesterol (TC) and LDLC concentrations compared with those presenting the first ACS (Figure 1). So, these patients with recurrent ACS with lower TC and LDL, but without changes on triglycerides and HDL, remains with a non-LDLcholesterol-dependent dyslipemia. When only the ACS patients treated with statins were analyzed (Table 2), the lipid profile results were identical. So, the correction of lipid profile by statin does not eliminate the non-LDL-dependent dyslipemia.

\begin{tabular}{|l|l|l|l|}
\hline & Previous IHD & No previous IHD & $\mathbf{p}$ \\
\hline TC $(\mathbf{m g} / \mathbf{d L})$ & $172.1(41.6)$ & $203.0(46.9)$ & 0 \\
\hline LDLc $(\mathbf{m g} / \mathbf{d L})$ & $110.2(39.6)$ & $136.4(44.9)$ & 0 \\
\hline HDLc $(\mathbf{m g}(\mathbf{d L})$ & $40.0(12.1)$ & $38.9(10.3)$ & 0.394 \\
\hline TG $(\mathbf{m g} / \mathbf{d L})$ & $145.8(65.3)$ & $171.8(88.6)$ & 0.144 \\
\hline
\end{tabular}

Table 2: Lipid profile of ACS patients treated with statins, according to a history of ischemic heart disease (IHD).

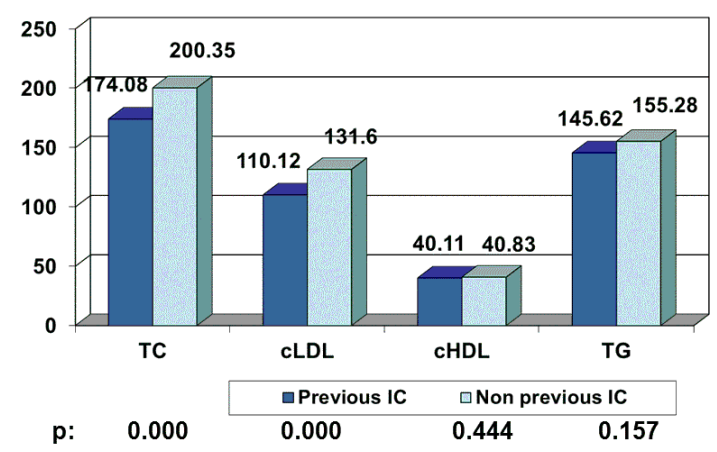

Figure 1: Lipid parameters in patients with acute coronary syndrome according to a history of Ischemic Heart Disease (IHD). Anova test.

The atherogenic ratios and significant differences can be found in all indexes, except for log (triglycerides)/HDLc (Figure 2). Patients with recurrent ACS had significantly lower non-HDLc levels, TC/ HDLc and LDLc/HDLc, but higher HDLc/TC and HDLc/LDLc ratios compared with first ACS patients. Again, when the atherogenic index profile was analyzed only in patients taking statins (Table 3 ), and 
Citation: Civeira MF, Pedro-Botet J, Pintó X, Zúñiga M, Mangas A, et al. (2015) Atherogenic Ratios in Patients with Recurrent Acute Coronary Syndrome and Receiving Statin Therapy: Clinical Usefullness as Cardiovascular Predictors. J Clin Exp Cardiolog 6: 358. doi: $10.4172 / 2155-9880.1000358$

Page 3 of 4

despite an improvement in the atherogenic ratios, the same significant differences persisted as in the overall group.

\begin{tabular}{|l|l|l|l|}
\hline & Previous IHD & No previous IHD & $\mathbf{p}$ \\
\hline Non-HDLc (mg/dL) & $131.9(40.2)$ & $164.1(45.7)$ & 0 \\
\hline TC/HDLc & $4.55(1.47)$ & $5.49(1.66)$ & 0.001 \\
\hline LDLc/HDLc & $2.95(1.34)$ & $3.70(1.47)$ & 0.005 \\
\hline HDLc/TC & $0.24(0.08)$ & $0.20(0.07)$ & 0 \\
\hline HDLc/LDLc & $0.42(0.20)$ & $0.33(0.17)$ & 0 \\
\hline Log (TG/HDLc) & $0.41(0.59)$ & $0.59(0.57)$ & 0.067 \\
\hline
\end{tabular}

Table 3: Atherogenic ratios in 633 ACS patients on statins, according to a history of ischaemic heart disease.

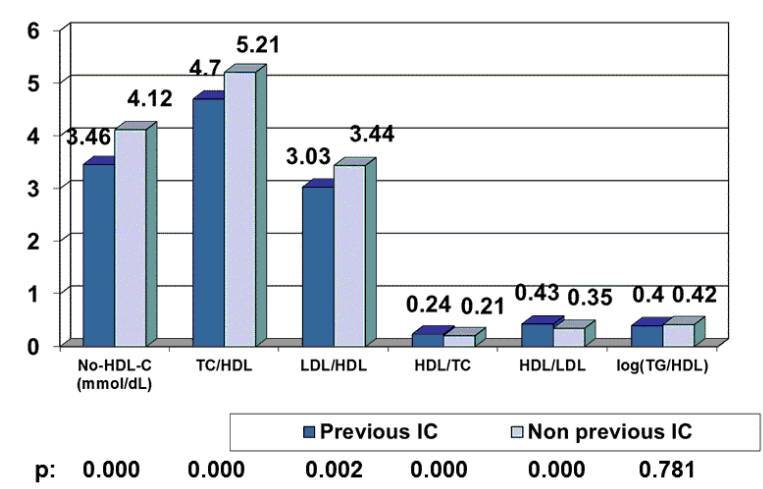

Figure 2: Atherogenic indexes in patients with acute coronary syndrome, according to a history of Ischemic Heart Disease (IHD). Anova test.

\section{Discussion}

As can be gathered from the results of the present study, patients with recurrent ACS, although the prevalence of smoking was lower, had a considerable and significantly higher frequency of other major risk factors such as hypertension and type-2 diabetes. Undoubtedly, these risk factors also contribute to residual vascular risk [16].

With regard to the ischemic clinical form of presentation, the first ACS event tended to be mainly myocardial infarction; however, angina was the most frequent type of recurrent ACS, representing over a third of these events.

Patients with recurrent ACS compared with those presenting a first ACS showed a more favorable lipid profile, with lower total cholesterol and LDLc and similar triglyceride and HDLc levels. These findings were related to prior statin therapy more frequently reported in patients with recurrent ACS. Statins are known to exert a powerful LDLc-lowering effect, but have a marginal effect on the remaining lipid parameters and therefore a residual vascular risk attributable to elevated triglycerides and low HDLc may persist.

In the present study, all ratios in which TC or LDLc were represented showed an improvement in patients on statins. No difference was observed in the index related to triglycerides and HDLc as these lipids were not modified since statin treatment had little effect on such parameters. The triglyceride/HDLc index has been reported to be highly predictive of a first ischemic heart disease eevent [17], mainly in overweight patients or those with type-2 diabetes or metabolic syndrome [18]. From the pharmacologic point of view, statins do not appear to exert any effect on this index. Thus, a strategy for reducing this index, such as the use of fibrates or nicotinic acid, can help to attenuate the risks attributable to atherogenic dyslipidemia (increase in triglycerides and decrease in HDLc) as already reported $[19,20]$.

Changes in the atherogenic indexes run parallel to modifications in lipid profile and reflect the effects of lipid-lowering drugs. Since statins are the most common hypolipemiant used, the un-modifiable triglyceride and HDLc concentrations account for the residual vascular risk in these patients. So, it has been suggested that there is evidence for not using LDLc alone as the only target for the treatment of patients with dyslipidaemia [21].

Patients treated with statins are especially significant with regards to the persistence of triglyceride above and HDLc below the objectives established as therapeutic objectives and $(150 \mathrm{mg} / \mathrm{dL}$ for triglycerides and $40 \mathrm{mg} / \mathrm{dl}$ for HDLc) for high-risk patients who have suffered an episode of ischaemic heart disease [22].

The significant decrease of total cholesterol and LDLc is accompanied by a significant decrease in atherogenic indices in patients with recurrent ACS. However, despite this improvement, new ischaemic events occur. In other words, despite a standard management of LDLc, a recurrence of ACS occurs in hypertriglyceridemic and low HDLc patients. This fact has been recently described in patients with acute coronary syndrome [23], although they had not been compared -as in our study- a population with and without a history of coronary episodes. The use of indices like coronary disease predictors has evidenced that, exactly, the simplest parameters that can be used (like total cholesterol and HDLc) have the same predictive power as others that are more complex, which include apoproteins [24]. In patients taking statins the absolute risk reduction does not eliminate residual risk; and the low HDLc that is found in patients with acute coronary syndrome [25] could play an important role to increase residual cardiovascular risk [26] a despite of others cardiovascular risk factors. Our study is focused on lipid profile and show the persistent dyslipemia non-LDL-cholesterol related.

The modifications in those ratios are sensitive to taking statins, in a way that those patients with a history of ischaemic heart disease and taking of statins improve their atherogenic indices thanks to the improvement of cholesterol figures and LDLc without modifying the triglycerides and HDLc. It is a key feature that the statin therapy is not sufficient to control global dyslipidemia a despite his effects on LDLcholesterol. This is the main concept around of residual vascular risk.

The atherogenic indices accurately and simply reflect the changes in the lipid profile, but are more expressive in detailing the persistence of residual lipid risk given that in such indices, lipid fractions that are not modified with standard treatment together with those that are modified by the previous lipid-lowering treatment, are included. This phenomenon is particularly significant in patients with recurrent ACS.

This is characteristic in patients with successive episodes of ischaemic heart disease. In other words, the risk of a coronary episode continues even improving some lipid parameters as well as the 
Citation: Civeira MF, Pedro-Botet J, Pintó X, Zúñiga M, Mangas A, et al. (2015) Atherogenic Ratios in Patients with Recurrent Acute Coronary Syndrome and Receiving Statin Therapy: Clinical Usefullness as Cardiovascular Predictors. J Clin Exp Cardiolog 6: 358. doi: $10.4172 / 2155-9880.1000358$

Page 4 of 4

atherogenic indices, and this is because of the persistence of such factors.

\section{References}

1. Lobos JM, Royo-Bordonada MA, Brotons C, Alvarez-Sala L, Armario P, et al. (2008) Comité Español Interdisciplinario para la Prevención Cardiovascular, Comité Español Interdisciplinario. European Guidelines on Cardiovascular Disease Prevention in Clinical Practice: CEIPC 2008. Rev Esp Salud Publica 82: 581-616.

2. Hayward RA, Hofer TP, Vijan S (2006) Narrative review: lack of evidence for recommended low-density lipoprotein treatment targets: a solvable problem. Ann Intern Med 145: 520-530.

3. Superko HR, King S III (2008) Lipid management to reduce cardiovascular risk: a new strategy is required. Circulation 117: 560-568.

4. Hsia SH, Pan D, Berookim P, Lee ML (2006) A population-based, crosssectional comparison of lipid-related indexes for symptoms of atherosclerotic disease. Am J Cardiol 98: 1047-1052.

5. Mc Queen MJ, Hawken S, Wang X, Ounpuu S, Sniderman A, et al (2008) For the INTERHEART study investigartors. Lipids, and lipoproteins, and apolipoproteins as risk markers of myocardial infarction in 52 countries: a case control study. Lancet 372: 224-233.

6. Ridker PM, Rifai N, Cook NR, Bradwin G, Buring JE (2005) Non-HDL cholesterol, apolipoproteins A-I and B100, standard lipid measures, lipid ratios, and CRP as risk factors for cardiovascular disease in women. JAMA 294: 326-333.

7. Ingelsson E, Schaefer EJ, Contois JH, McNamara JR, Sullivan L, et al (2007) Clinical utility of different lipid measures for prediction of coronary heart disease in men and women. JAMA 298: 776-785

8. Kastelein JJ, van der Steeg WA, Holme I, Gaffney M, Cater NB, et al. (2008) Lipids, apolipoproteins, and their ratios in relation to cardiovascular events with statin treatment. Circulation 117: 3002-3009.

9. Millán J, Pintó X, Muñoz A, Zúñiga M, Rubiés-Prat J, et al. (2009) Lipoprotein ratios: Physiological significance and clinical usefulness in cardiovascular prevention. Vasc Health Risk Manag 5: 757-765.

10. Kinosian B, Glick H, Garland G (1994) Cholesterol and coronary heart disease: predicting risks by levels and ratios. Ann Intern Med 121: 641-647.

11. Liem AH, van de Woestijne AP, Roeters van Lennep HW, Zwinderman $\mathrm{AH}$, van der Steeg WA, et al. (2008) ApoB/A1 and LDL-C/HDL-C and the prediction of cardiovascular risk in statin-treated patients. Curr Med Res Opin 24: 359-364.

12. Ray KK, Cannon CP, Cairns R, Morrow DA, Ridker PM, et al. (2009) Prognostic utility of apoB/AI, total cholesterol/HDL, non-HDL cholesterol, or hs-CRP as predictors of clinical risk in patients receiving statin therapy after acute coronary syndromes: results from PROVE ITTIMI 22. Arterioscler Thromb Vasc Biol 29: 424-430.

13. The Joint European Society of Cardiology/American College of Cardiology Committee (2000) Myocardial infarction redefined- A consensus document of the Joint European Society of Cardiology/ American College of Cardiology Committee for the redefinition of myocardial infarction. Eur Heart J 21: 1502-1513.

14. Thygesen K, Alpert JS, White HD, on behalf of the Joint ESC/ ACCF/AHA/WHF (2007) Task Force for the Redefinition of Myocardial Infarction. Universal definition of myocardial infarction. Eur Heart J 28: 2525-2538.

15. Friedewald WT, Levy RI, Fredrickson DS (1972) Estimation of the concentration of low-density lipoprotein cholesterol in plasma, without use of preparative ultracentrifuge. Clin Chem 218: 499-502.

16. Fruchart JC, Sacks F, Hermans MP, Assmann G, Brown WV, et al. (2008) The Residual Risk Reduction Initiative: A call to action to reduce residual vascular risk in patients with dislypidemia. Am J Cardiol 102: 1000-34000.

17. Cordero A, Andres E, Ordoñez B, León M, Laclaustra M, et al. (2009) Usefulness of triglycerides-to high-density-lipoprotein colesterol ratio for predicting the first coronary event in men. Am J Cardiol 104: 1393-1397.

18. Cordero A, Laclaustra M, Leon M, Casasnovas JA, Grima A, et al. (2008) Comparison of serum lipid values in subjects with and without the metabolic syndrome. Am J Cardiol 102: 424-428.

19. Lee M, Saver JL, Towfighi A, Chow J, Ovbiagele B (2011) Efficacy of fibrates for cardiovascular risk reduction in persons with atherogenic dyslipidemia: a meta-analysis. Atherosclerosis 217: 492-498.

20. Bruckert E, Labreuche J, Amarenco P (2010) Meta-analysis of the effect of nicotinic acid alone or in combination on cardiovascular events and atherosclerosis. Atherosclerosis 210: 353-361.

21. Geoffrey A (2007) Modest lack of evidence for recommended low-density lipoprotein cholesterol treatment targets. Ann Intern Med 146: 614.

22. Catapano AL, Reiner Z, De Backer G, Graham I, Taskinen MR, et al. (2011) ESC/EAS Guidelines for the management of dyslipidaemias The Task Force for the management of dyslipidaemias of the European Society of Cardiology (ESC) and the European Atherosclerosis Society (EAS). Atherosclerosis 217: 3-46

23. Carey VJ, Bishop L, Laranjo N, Harshfield BJ, Kwiat C, et al. (2010) Contribution of high plasma triglycerides and low high-density lipoprotein cholesterol to residual risk of coronary heart disease after establishment of low-density lipoprotein cholesterol control. Am J Cardiol 106: 757-763.

24. Millan Nuñez-Cortes J, Pedro-Botet Montoya J, Pinto Sala X (2011) Riesgo residual vascular de origen lipídico. Estrategias para el tratamiento del riesgo residual por dislipemia aterogénica. Clin Invest Arterioscl 23: 230-239.

25. Pinto X, Millan J, Muñoz A, Hernández-Mijares A, Zuñiga M, et al. (2010) A very high prevalence of low HDL cholesterol in Spanish patients with acute coronary síndromes. Clin Cardiol 33: 418-423.

26. Cziraky MJ, Watson KE, Talbert RL (2008) Targeting low HDLcholesterol to decrease residual cardiovascular risk in the managed care setting. J Manag Care Pharm 8: S3-28. 